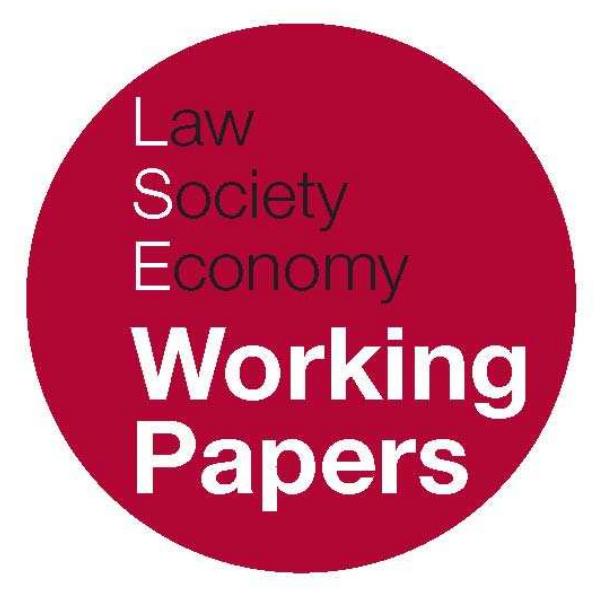

\title{
The EU Chemicals Policy: Towards \\ Inclusive Governance?
}

\author{
Veerle Heyvaert
}

LSE Law, Society and Economy Working Papers 7/2008

London School of Economics and Political Science

Law Department

This paper can be downloaded without charge from LSE Law, Society and Economy Working Papers at: www.lse.ac.uk/collections/law/wps/wps.htm and the Social Sciences Research Network electronic library at: http://ssrn.com/abstract=1111968.

(C) Veerle Heyvaert. Users may download and/or print one copy to facilitate their private study or for non-commercial research. Users may not engage in further distribution of this material or use it for any profit-making activities or any other form of commercial gain. 


\title{
The EU Chemicals Policy: Towards Inclusive Governance?
}

\author{
Veerle Heyvaert ${ }^{*}$
}

\begin{abstract}
This paper investigates to what extent contemporary EU risk regulation responds to demands for inclusive governance. To this end, the paper examines the new EU regulatory framework for the control of chemicals, better known as the REACH Regulation. It identifies and evaluates opportunities for public participation during the negotiation of the REACH proposal (the 'input' stage), in decision-making processes under the REACH Regulation ('throughput'), and at the stage of reviewing decisions taken in compliance with REACH ('output'). The paper argues that formal opportunities for public participation exist and are reasonably satisfactory, but that their significance is eroded by the institutional and functional context in which participation must take place.
\end{abstract}

\section{INTRODUCTION}

This contribution analyses contemporary European risk regulation as an arena for inclusive governance, concentrating on the regulatory regime for the control of chemical risks. The focus on chemicals is rewarding for a number of reasons. First, the threats to health, safety and the environment posed by dangerous chemicals, and the abiding uncertainties surrounding the links between chemical exposure and health and environmental degradation, have long elicited high levels of public concern. Moreover, since the risks attach to the chemicals themselves, rather than to a side effect of commercial enterprise as is the case for, say, the risks of air pollution caused by industrial emissions, measures introduced to manage and reduce these risks tend to have a very direct impact on the marketability of

\footnotetext{
* An earlier version of this paper was presented in June 2007 at the CONNEX workshop on European Risk Governance: Its Science, Its Inclusiveness and Its Effectiveness (Maastricht University). The paper is also available as a chapter in E. Vos, European Risk Governance: Its Science, Its Inclusiveness and Its Effectiveness (CONNEX Report Series N. 6, 2008).
} 
commercial wares. Thus, the various interests that inform the shape and substance of market regulation -- ranging from competitiveness, innovation, and market stability and fairness, to worker, consumer, and environmental protection -collide in chemical risk decision-making in a highly visible and explicit way. ${ }^{1}$ Finally, since the EU regulatory framework for the production, marketing and use of chemicals has recently undergone a major overhaul, it offers a good insight into how and the extent to which notions of inclusiveness are currently being integrated into governance of the European market.

The analysis will show that, formally at least, the EU regulatory regime for chemicals control is far more inclusive than its predecessor. However, when looking below the surface of formal arrangements, and particularly taking into account that the effectiveness of inclusion is determined not only by the creation of entry points into the regulatory debate, but equally by determinations of what is debatable, it is unlikely that the chemicals control regime will foster effective participatory decision-making.

Before reviewing the current 'REACH' regime for chemicals control, the paper briefly goes over the salient features of the old regime, and adds some information on its level of inclusiveness. It then summarily maps out the key features of the recently adopted REACH Regulation before turning to the core of the analysis, which examines the inclusiveness of REACH at the different stages of 'input' (ie, participation in the negotiation and adoption of REACH), 'throughput' (participation in the decision-making processes taking place under the REACH framework) and 'output' (participation in the critical evaluation of regulatory decisions taken under REACH). This analysis then forms the basis for a critical review of REACH's provision for public participation, which critique extends the idea of inclusiveness to take into account the scope and integrative structure of the regulatory framework.

\section{THE OLD REGIME FOR CHEMICALS CONTROL IN THE EUROPEAN UNION}

Prior to 2007, the control of chemicals in the EU was governed by a network of Directives and Regulations. ${ }^{2}$ The old system operated on the basis of a double distinction, first, between dangerous substances/preparations and other chemicals and, ${ }^{3}$ second, between old or 'existing' substances, and substances introduced on

\footnotetext{
1 Cf V. Heyvaert, 'No Data, No Market. The Future of EU Chemicals Control under the REACH Regulation' (2007) 9 Environmental Law Review 201.

2 See generally V. Heyvaert, Coping With Uncertainty. The Regulation of Chemicals in the European Union (PhD Dissertation, European University Institute, Florence, Italy, 1999).

3 Dangerous chemicals: chemicals falling into one of the hazard categories set out in Community law (expanded from 8 initially to 15 now). Identification of a chemical as dangerous entails imposition of a range of risk management requirements: classification, R-Phrases and S-phrases, packaging, labelling, enclosing safety data sheets to be passed on to professional users, worker safety obligations, etc.
} 
the EU market after September 1981 or 'new substances'. The latter distinction was mostly the result of political and economic expediency. As awareness grew throughout the 1970s that the availability of timely and reliable information concerning the health and environmental impacts of the release of chemical substances was crucial for the design of a risk management framework that had a fighting chance of effectiveness, EU institutions conditioned market access upon the notification of a voluminous technical dossier to the competent authority located in the Member State where a manufacturer or importer first sought to market a new chemical, or a preparation containing a newly engineered substance. In exchange for the new information production and supply burdens, manufacturers and importers gained a one-stop shop facility, whereby a single notification would be recognised by all Member States. ${ }^{4}$ For chemicals that were already in circulation however, the imposition of information supply and testing requirements was considered too onerous and potentially disruptive to the economy. ${ }^{5}$ Hence, during the first decade after notification duties were introduced, EU law did not foster information supply concerning existing chemicals in a systematic way. The notification requirement, and the absence of a counterpart for existing substances, was a textbook example of a regulatory control mechanism that favours the old over the new. ${ }^{6}$ In addition to stifling innovation, the approach was undesirable from a health and environmental protection perspective, since old chemicals tend to pose greater risks than newer generations of substances.

The Member State competent authority was the pivotal actor in the notification process. Importers and manufacturers submitted technical dossiers to the national authorities, which were in charge of checking the completeness of the file, and circulating it to the Commission and the other Member States for review. Furthermore, as of the early 1990s, EU law instructed national authorities to perform a risk assessment on the basis of the information in the technical dossier, in accordance with newly enacted Community risk assessment standards. ${ }^{7}$ The risk recommendations flowing from the risk assessment could constitute a basis for regulatory action, either at the Community level or, residually, at the Member State level. ${ }^{8}$ At the EC level, such regulatory intervention would typically take the form of a new restriction on marketing and use, adopted via legislative amendment of Directive $76 / 769 /$ EEC on the approximation of the laws, regulations and

\footnotetext{
4 Council Directive 79/831/EEC amending for the sixth time Directive 67/548/EEC on the approximation of the laws, regulations and administrative provisions relating to the classification, packaging and labelling of dangerous substances [1979] OJ L259/10.

5 Twelve years later, the Existing Substances Regulation would try to correct the information deficit concerning chemicals for which no notification dossier had been submitted. However, as will be discussed further below, the information supply obligations in the Regulation were never properly enforced.

${ }^{6}$ Cf R. Stewart, 'Regulation, Innovation and Administrative Law: A Conceptual Framework' (1981) 69 California Law Review, 1259.

${ }^{7}$ Commission Directive 93/67/EEC of 20 July 1993 laying down the Principles for Assessment of Risks to Man and the Environment of Substances Notified in accordance with Council Directive 67/548/EEC [1993] OJ L227/9.

${ }^{8}$ C-473/98 Toolex Alpha [2000] ECR I-9741; V. Heyvaert, 'Balancing Trade and Environment in the European Union: Proportionality Substituted? (2001) Journal of Environmental Law 392, 395-398.
} 
administrative provisions of the Member States relating to Restrictions on the Marketing and Use of Certain Dangerous Substances and Preparations (Marketing and Use Restrictions Directive).?

As mentioned above, the situation was different for existing substances. Very little was (and still is) known about most of the 30,000 chemicals that have been regularly traded since before September 1981. To address this data gap, the Council adopted Regulation (EEC) 793/93 on the Evaluation and Control of the Risks of Existing Substances (Existing Substances Regulation). ${ }^{10}$ The data gathering approach established therein was distinctly more centralised than in the framework of notification. Pursuant to the Existing Substances Regulation, manufacturers and importers were to report all available chemical data directly to the European Commission. The various submissions were collected by the European Chemicals Bureau, ${ }^{11}$ established under the auspices of the Joint Research Centre Environment Institute, which processed everything into a comprehensive, EU-wide database ('EUCLID'). The information in the EUCLID then constituted the starting point for a priority setting exercise. The Commission drew up priority lists enumerating those substances which, on the basis of available information, had the highest risk potential. These substances were assigned to different Member States for further data gathering and risk assessment. The Member States authorities, acting as delegates to the Commission, would report their findings back to the Commission in the form of a risk recommendation. If the risk recommendation indicated that regulatory interventions were necessary to control identified health and/or environmental risks, the Commission would draft a legislative proposal for risk reduction, either under the Marketing and Use Restrictions Directive, or under an alternative EU regulatory framework (for instance, the Control of Chemicals Agents at Work Directive ${ }^{12}$ ). In contrast to the notification procedure, which after a few years performed reasonably well, the Existing Substances Regulation failed to deliver. It would exceed the scope of this paper to scrutinise the different factors that led to the failure of the existing substances regime, however, in the framework of this analysis it should be noted that the absence of either positive or (credible) negative incentives for the chemical sector to cooperate in the regime fatally crippled the Regulation. ${ }^{13}$ This serves as a reminder that no matter how formally binding, rules are vulnerable. Hence, the greater legitimacy that inclusiveness aspires to convey is not only normatively attractive, but can crucially influence regulatory effectiveness.

\footnotetext{
9 [1976] OJ L262/201.

10 [1993] OJ L84/1.

11 See Commission Communication to the Council and the EP - The European Chemicals Bureau [1993] OJ $\mathrm{C} 1 / 3$.

12 [1998] OJ L131/11.

13 V. Heyvaert, 'Guidance Without Constraint. Assessing the Impact of the Precautionary Principle on the European Community's Chemicals Policy' (2006) 6 Yearbook of European Environmental Law 27, 46; and Royal Commission on Environmental Pollution, 'Twenty Fourth Report - Chemicals in Products. Safeguarding the Environment and Human Health" 26 June 2003, published on the Internet at: http:/ / www.rcep.org.uk/chemicals.ch00-rep.pdf.
} 
As is already apparent from even a snapshot overview, the old regime was institutionally dominated by public authorities, in the first place national regulatory authorities (NRAs). NRAs administered the notification process, performed risk assessments for new substances and, as rapporteurs, for existing ones post-1993, and through the process of Council amendment were intimately involved in the negotiation and adoption of new and tighter restrictions. The Commission, too, played a prominent role, as it orchestrated the data gathering and evaluation regime under the Existing Substances Regulation and, with rather more success, formulated and adopted harmonised classifications for dangerous substances. This representation does somewhat understate the inclusiveness of the old regime, particularly with regard to the involvement of chemicals producers and importers. The notification provisions under Directive 67/548, as amended, offered notifiers the opportunity to prepare and submit a preliminary risk assessment. Moreover, traders were required to formulate and affix a preliminary classification for the dangerous chemicals they were trading. More generally, while imposing a regulatory burden, producers' and importers' responsibility for information supply, both in the context of notification and for existing substances, simultaneously created an access point to regulatory decision-making processes that were facilitated by data supply. ${ }^{14}$ Even though formal guarantees were thin on the ground, the chemical sector was usually informally and at times extensively consulted prior to, for instance, the formulation of a harmonised classification. However, the lack of formal provisions for participation did keep private parties dependent on goodwill rather than entitlement and, importantly, meant that parties external to the data supply, evaluation and decision-making process, such as public interest NGOs, had even more limited opportunities of engagement.

The preceding paragraphs offer a rudimentary sketch of the Community approach to chemical risk regulation between 1980 and 2007. REACH, however, has brought about a transformation of regulatory chemicals control, and arguably even of the EU's approach to complex risk governance more broadly. The following sections briefly review the main features of REACH, and then concentrate on the question of inclusiveness.

\section{REACH}

On 1 December 2006, the Environment Committee of the European Parliament (EP ENV) and representatives of the Council of Ministers agreed on a compromise text on REACH, the new and controversial regulatory framework for the control of chemical substances in Europe. The REACH Regulation, ${ }^{15}$ as duly

${ }^{14}$ C. Arup, 'Chemical Notification Laws in the OECD Member Countries' (1987) Journal of World Trade Law 47, 65 .

15 Regulation (EC) No 1907/2006 of the European Parliament and of the Council of 18 December 2006 concerning the Registration, Evaluation, Authorisation and Registration of Chemicals (REACH), 
voted on by the EP plenary on 11 December and adopted by the EP and Council on 18 December, entered into force on 1 June 2007. Its provisions will be gradually implemented over a period spanning from now until 2018.

REACH stands for the Registration, Evaluation, Authorisation and Restriction of Chemicals. REACH is intended to provide an encompassing regulatory framework that enables information production and decision-making relating to all chemicals produced and/or circulating in the EU market, ${ }^{16}$ covering every stage of the chemicals production and use cycle. The information allows identification of dangerous chemicals, a cost-effective assessment of the risks posed by the production, marketing, use, and disposal of such chemicals, and the development of cradle-to-grave risk management policies, which must be passed on and refined through the chemicals supply chain. The following sections give a short description of the salient features of the REACH Regulation, covering registration, evaluation, authorisation, risk reduction, institutional design, and enforcement. ${ }^{17}$

\section{REGISTRATION 18}

REACH's philosophy is that no chemical substance, in whatever form, should circulate on the market without adequate documentation. To this effect, REACH imposes a generalised registration requirement: manufacturers or importers of chemicals produced or imported in volumes of over 1 tonne per year must apply for registration, which is conditioned on the submission of a technical data file supplying health, safety, and environmental information. Registration extends previous data reporting requirements ${ }^{19}$ in a number of significant ways. Most importantly, registration targets the roughly 30,000 chemicals which have been traded in substantial volumes within Europe for over 25 years, but for which scant or no information is available. ${ }^{20}$ Moreover, Registration affects chemicals substances as well as chemicals in preparations ${ }^{21}$ and in articles. This means that registration duties not only fall upon chemicals manufacturers and importers, but also on the vast groups of traders selling goods that contain chemicals, ranging from cars to disposable lighters.

establishing a European Chemicals Agency, amending Directive 1999/45/EC and repealing Council Regulation (EEC) No 793/93 and Commission Regulation (EC) No 1488/94 as well as Council Directive 76/769/EEC and Commission Directives 91/155/EEC, 93/67/EEC, 93/105/EC and 2000/21/EC [2006] OJ L396/1.

${ }^{16}$ Provided they are not covered by other, more specific Community legislation, such as Directive 91/414 (pesticides) and Directive 98/8 (biocides).

${ }^{17}$ See also n 1 above, 201-6, and the detailed yearly overviews by C. Garcia Molyneux on 'Substantive European Community Law - Chemicals' (2005-2008) Yearbook of European Environmental Law, vols. 5 onwards.

${ }^{18}$ REACH Reg., n 15 above, Title II.

${ }^{19}$ See Part II above.

${ }^{20}$ See Part II in fine.

${ }^{21}$ E.g., detergents. 


\section{EVALUATION 22}

The data gathering requirements under REACH connect to the framework's second risk management stage: the evaluation procedure. Evaluation covers the evaluation of dossiers submitted pursuant to registration, which is compulsory for those containing proposals for animal testing in order to minimise duplication testing data by more than one registrant. Substance evaluation, in turn, is carried out when initial data raise suspicions concerning the health and/or environmental impact of chemicals. An EU-wide rolling action plan will be established, where substances targeted for evaluation are allocated to a Member State that acts as rapporteur. Where suspicions are confirmed, evaluation may trigger further risk management actions, such as the inclusion of the chemical on the list of substances subject to authorisation, or the drafting of risk reduction measures.

\section{AUTHORISATION ${ }^{23}$}

The most controversial pillar of REACH is the authorisation requirement for highly dangerous chemicals, such as CMRs, ${ }^{24} \mathrm{PTBs}^{25}$ and vPvBs. ${ }^{26}$ After the lapse of a sunset date, those chemicals that have been identified as subject to an authorisation requirement can only be produced, traded and/or used if Commission approval has been obtained. It is incumbent on the private applicant for authorisation to furnish proof, in the form of an extensive data file including a risk assessment and risk management recommendations, that the risks posed by the chemical are either adequately contained, or that no usable alternatives currently exist but substitutes are being investigated. Applications are reviewed by the newly established European Chemicals Agency (ECHA), which produces an opinion for the Commission. According to the wording of the REACH Regulation, if the risks are shown to be adequately contained, the Commission must authorise. If, on the other hand, it is impossible fully to contain the risks, the Commission may grant authorisation, depending on the severity of the risk and viability of alternatives. Authorisations are subject to review and monitoring.

\section{ManufaCture, MARKeting AND Use Restrictions ${ }^{27}$}

A risk management alternative to authorisation is the adoption of Communitywide restrictions curbing the production, marketing and/or use of dangerous chemicals. The REACH Regulation both incorporates pre-existing measures, which were enacted in the 1976 Marketing and Use Restrictions Directive and

\footnotetext{
22 REACH Reg., n 15 above, Title VI.

23 ibid, Title VII.

24 Carcinogens, mutagens and substances toxic to reproduction.

25 Persistent, toxic and bioaccumulative substances.

26 Very persistent, very bioaccumulative substances.

27 REACH Reg., n 15 above, Title VIII.
} 
ensuing amendments, and maps out the process for the adoption of new restrictions. As with authorisation, risk reduction measures are adopted by the Commission acting on an ECHA opinion. Before REACH, the adoption of each new restrictive measure required Council (and, after Maastricht, Council and European Parliament (EP)) decision-making, ${ }^{28}$ which slowed down the introduction of chemical risk measures to the point of ineffectiveness. ${ }^{29}$ The shift towards a Commission decision-making process is intended to speed up this process, and thus deliver a higher level of up-to-date health and environmental protection standards. Interestingly, the procedure designated for the adoption of restrictions is the new 'regulatory procedure with scrutiny', which was introduced in a 2006 amendment to the 1999 Comitology decision. ${ }^{30}$ The regulatory procedure with scrutiny responds to demands for greater EP involvement in Commission decision-making. ${ }^{31}$ It is the sole comitology procedure where agreement between the Commission and the consulted Committee of national representatives does not automatically result in adoption of the Commission proposal. Instead, even Committee-approved proposals are forwarded to the EP and the Council 'for scrutiny', which may oppose the proposal by simple (EP) or qualified majority (Council) respectively. The regulatory procedure with scrutiny certainly provides a high level of accountability of the Commission and Committee vis-à-vis the primary EU law-makers. However, checks and balances make for lengthy procedures, and we might wonder whether this new form of comitology will still be able to deliver results more efficiently than the Council and EP decision-making process which it replaces.

\section{INSTITUTIONAL DESIGN}

With the new standards and procedures mapped out in REACH comes a new institutional design to manage the regulatory framework. Most importantly, the REACH Regulation establishes the European Chemicals Agency (ECHA), 32 which will function as both the designated supplier of scientific expertise and opinions to the Commission, and the chief administrator of the scheme. Whereas formerly Member State national authorities were the first point of contact with private parties complying with EU regulatory requirements, and thus the chief liaison with Community authorities, applicants for registration under REACH directly submit their applications to ECHA, which will: review registration dossiers; check the completeness of the file and, where necessary, request additional information; perform the registration; and assign a registration number. In the case of applications for authorisation, applicants submit to ECHA, which then

\footnotetext{
28 Article 251 EC.

${ }^{29}$ n 13 above.

30 Council Decision 2006/512/EC amending Decision 1999/468/EC laying down the Procedures for the Exercise of Implementing Powers conferred on the Commission [2006] OJ L200/11.

31 D. Pocklington, 'Comitology Under Greater Scrutiny (2006) 15 European Environmental Law Review 306.

32 REACH Reg., n 15 above, Title 10.
} 
orchestrates the scientific review of the technical file and risk assessment submitted by the applicant, and drafts a recommendation for the Commission. Member State involvement in the process is primarily arranged through a permanent Member State Committee under ECHA's auspices. As mentioned before, the Commission takes the lead in decisions relating to substance evaluation and its outcome, and decides on authorisations, as well as on restrictions on manufacture, marketing, and use. Member States do however have an opportunity to be closely involved in the identification of substances for evaluation, and perform the crucial task of substance evaluation. Additionally, the Member State is represented in Commission decision-making through the familiar channel of comitology.

This brief overview cannot do justice to the delicate balances and intricacies that the institutional settlement under REACH reflects. In broad terms, however, REACH could be said to represent an exercise in regulatory centralisation, as both the pivotal administrative and decision-making functions are exercised by Community institutions (respectively, ECHA and the Commission). Also, and perhaps of even greater importance, whereas before REACH communications between public authority and the private sector where predominantly conducted through the intermediary of national regulatory authorities, REACH not only enables but even requires a direct dialogue between EU institutions and regulatory addressees. Shifting patterns of communication can fundamentally affect the relationships and relative dependencies between the various actors in a regulatory network. In the REACH scenario, they could in the long run contribute to the diversion of familiarity, allegiance, recognition of regulatory practice and even authority from the national to the European level.

\section{ENFORCEMENT}

REACH firmly embraces a policy of 'no data, no market'. After the transition dates have passed, any unregistered chemical (or chemical use) should be taken out of circulation. For old or 'existing' chemicals, this daunting penalty for nonregistration is precisely what distinguishes registration from preceding data reporting duties under the Existing Substances Regulation, the failure of which to deliver results was broadly attributed to the absence of a credible threat in case of non-compliance. ${ }^{33}$ Hence, the credibility of REACH as a workable system for risk control, both within the EU and on the global scene, will hinge largely on the effectiveness with which regulatory provisions are enforced. This is where the role of the Member State is crucial, as enforcement of the REACH requirements is entirely a national responsibility.

33 n 13 above. 


\section{INCLUSIVE GOVERNANCE IN REACH}

As a prominent strand of the pervasive discourse on 'good governance' which has so dominated the last ten years of EU regulatory studies, the most commonly understood version of inclusive governance focuses on the question of how, and to what extent, different stakeholders get to represent their interests and participate in the process of law- and decision-making. ${ }^{34}$ For reasons that have been thoroughly discussed elsewhere, attention tends to centre around those stakeholders and interests that, although affected by regulatory processes and their outcomes, traditionally had very limited opportunities for direct engagement. ${ }^{35}$ Often, such categories of stakeholders are loosely grouped under denominations such as 'the public', 'the public interest', or 'civil society' -- terms which all construe oversimplified but workable representations of those entities that do not have a privileged status in regulatory decision-making by virtue of authority or specific designation in the regulatory framework.

The analysis below follows this format as it looks at opportunities for private stakeholders, and particularly stakeholders that are not the direct addressees of the regulatory prescriptions in the REACH Regulation, to be involved in the regime for chemical risk control, in terms of its development (input), its operation (throughput), and vis-à-vis the decisions it generates (output).

\section{INPUT}

The history of the REACH reform is one of extensive consultation and debate. From its inception, REACH was a pronouncedly high-profile enterprise. Speaking before the plenary, Head of EP ENV Committee Karl-Heinz Florenz called REACH 'one of the largest and most significant reports' ever to be debated within EP Chambers. ${ }^{36}$ The level of interest and controversy surrounding the initiative was, first of all, a function of its scale, as REACH was the outcome of a review process that had begun in 1998 and which involved no less than four key pieces of EC internal market legislation: Directive 67/548 on the Classification, Packaging and Labelling of Dangerous Substances; ${ }^{37}$ Directive 88/379 on Dangerous

\footnotetext{
34 See Commission White Paper on European Governance COM(2001)428, 25 July 2001; Commission Communication - Towards a Reinforced Culture of Consultation and Dialogue: General Principles and Minimum Standards for Consultation of Interested Parties by the Commission COM(2002)704, 11 Dec. 2002; Commission Communication - European Governance: Better Lawmaking COM(2002)275, 5 June 2002; Commission Communication - A Strategic Review of Better Regulation in the European Union COM(2006)689, 11 Nov. 2006. See D. Obradovic \& J. M. Alonso Vizcaino, 'Good Governance Requirements concerning the Participation of Interest Groups in EU Consultation' (2006) 43 CMLR 1049; D. Curtin (ed.), Reflections on Concepts, Institutions and Substance (Antwerp: Intersentia, 2005); and S. Smismans (ed.), Civil Society and Legitimate European Governance (Cheltenham: Edward Elgar, 2006).

35 ibid.

${ }^{36}$ M. Florenz, Head of the Committee on the Environment, Public Health and Food Safety, speaking before the Plenary of the EP discussing the proposed REACH Regulation, 15 Nov. 2005, published on the Internet at: http://www.europarl.europa.eu/members/public/yourMep/view.do?name= florenz\&partNumber $=1 \&$ language $=\mathrm{EN} \& \mathrm{id}=1038$.

37 [1967] OJ 196/1.
} 
Preparations; 38 the 1993 Existing Substances Regulation; ${ }^{39}$ and Directive 76/769 on Marketing and Use Restrictions for Dangerous Chemicals. ${ }^{40}$ The review process was a prominent and early example of the Commission's willingness to orchestrate broad-based consultation and some level of participation in policy reform initiatives, which obviously further raised stakeholder awareness of the impending changes. ${ }^{41}$

Going on from there, every further step leading up to the adoption of what would become known as the REACH Regulation, along landmarks such as the 2001 Commission White Paper on a Strategy for a Future Chemicals Policy, ${ }^{42}$ the 2003 release of the Commission Proposal for a REACH Regulation, ${ }^{43}$ and a range of impact assessments to gauge the anticipated regulatory costs and benefits of proposed risk control schemes, was accompanied by a high level of intensive, at times acrimonious, but reasonably transparent public debate. Moreover, this debate was fuelled by an impressive array of different actors, including domestic and non-EU chemical industry associations, representatives of small- and medium-sized businesses, consumer organisations, national EU and non-EU governments, environmental NGOs, trade unions, IGO and regional organisations, research institutes, academics, etc.

It would be disingenuous to claim that the process was insufficiently inclusive or accessible; the great pains that the Commission, for one, took broadly to consult and respond to the issues raised indicate otherwise. In fact, we could very plausibly hold up the REACH reform process as a blue print for participatory lawmaking. Yet, equal opportunities for access to not imply equal opportunities for influence. Pesendorfer has argued that, while consultation was formally inclusive, the terms of the debate, and the regulatory context in which it took place, favoured the promotion of private over public interest perspectives, and of economic over health and environmental considerations. ${ }^{44}$ We will revisit this connection between access to and context of the debate when considering the impact of the scope and risk management prescription in REACH on inclusive governance.

\footnotetext{
38 [1988] OJ L187/14.

39 [1993] OJ L84/1.

40 [1976] OJ L262/201. See Commission Working Document - Report on the operation of Directive 67/548/EEC, Directive 88/379/EEC, Regulation (EEC) 793/93, Directive 76/769/EEC SEC(1998)1986, 18 Nov. 1998.

${ }^{41}$ Cf D. Pesendorfer, 'EU Environmental Policy Under Pressure: Chemicals policy Change Between Antagonistic Goals?' (2006) 15 Environmental Politics 95, 105-108.

${ }^{42} \operatorname{COM}(2001) 88,27$ Feb. 2001.

43 Proposal for a Regulation of the European Parliament and of the Council concerning the Registration, Evaluation, Authorisation and Restriction of Chemicals (Reach), establishing a European Chemicals Agency and amending Directive 1999/45/EC and Regulation (EC) \{on Persistent Organic Pollutants\} \{SEC(2003 1171\} COM(2003)644, 29 Oct. 2003.

${ }^{44} \mathrm{n} 41$ above, 111
} 


\section{THROUGHPUT}

A key question in examining the inclusiveness of the REACH framework inquires into the extent to which different interests and stakeholders are represented in decision-making pursuant to REACH. As indicated before, REACH comprises a range of decision-making procedures, going from procedures to determine whether a registration is complete, and hence whether a registration number can be assigned which validates a product's new or continued circulation on the EU market, to the identification of highly dangerous chemicals that should be authorised, the authorisation itself, and the adoption of risk reduction measures for substances that are not subject to authorisation but nonetheless pose unacceptable risks. To gain a preliminary insight into the level of inclusive risk governance under REACH, this paper focuses on the interplay between institutions and interests taken into account in the authorisation process of a substance identified as falling under the authorisation requirements. Admittedly, authorisation constitutes but one pillar of the REACH framework; a complete picture of the organisation and degree of inclusiveness of the contemporary EU chemicals control regime, as an example of modern risk regulation, would additionally require the consideration of consultation and participation provisions in the registration, evaluation, authorisation identification, and risk reduction processes. However, since selectiveness cannot be avoided within the confines of a paper, the focus on the authorisation process is warranted because this process involves the marketing and use of precisely those chemicals that generate the highest level of public concern. Consequently, authorisation is the regulatory process in which the public arguably has the strongest interest in participating, and where exclusion from decision-making is least justifiable. The authorisation procedure therefore is a good indicator of the degree of inclusiveness aspired to under REACH, and of the likelihood of effectiveness.

\section{Stage 1: Application}

For purposes of simplicity, we can divide the authorisation process into three segments: the application, review, and decision-making stages. ${ }^{45}$ In each of the three stages, a different player assumes the lead in the authorisation process. Applications are formally industry-led: it is incumbent upon manufacturers, importers or downstream users to prepare and submit the application dossier. In practice, dossier preparation will be predominantly expert-driven, as the central documents are a chemical safety report (or risk assessment) covering the risks to human health and the environment from the use of the substance arising from its intrinsic properties, and an analysis of alternatives including, where appropriate, research and development activities undertaken by the applicant. With regard to

45 It should be noted that the authorisation process itself is preceded by another decision-making sequence, namely decision-making on the inclusion or exclusion of substances in Annex XIV, which lists substances subject to authorisation. See REACH Reg., n 15 above, Arts. 55-59. 
the chemical safety report, Annex I.0.2. stipulates that the assessment 'shall be prepared by one or more competent person(s) who have appropriate experience and received appropriate training,' The chemical safety report follows the traditional science-based risk assessment pattern of human, physico-chemical and environmental hazard assessment, ${ }^{46}$ exposure assessment, and risk characterisation. It is interesting to note that the required description of exposure scenarios, which map out the conditions under which the substance is manufactured and/or used, is to include 'a description of both the risk management measures and operational conditions which the manufacturer or importer has implemented or recommends to be implemented by downstream users.' This creates scope for existing risk management information, which is generated and developed in a practically applied context, to be integrated within the science-based assessment process and influence the ultimate risk characterisation. This risk characterisation, ultimately, compares the predicted or known exposure with the DNEL ${ }^{47}$ (human health) and/or PNEC (environmental health), ${ }^{48}$ and assesses the likelihood and severity of an event occurring due to the physico-chemical properties of the substance (such as explosiveness and flammability). If exposure does not exceed the DNEL and/or PNEC, and if risks relating to the substance's physico-chemical properties are negligible, the risks posed by the substance are considered 'adequately controlled', which crucially affects the outcome of the authorisation process. However, before turning to those, it should be observed that Article 62(5) of the REACH Regulation allows applicants to include a socio-economic analysis in the application dossier, which broadens the scope for alternative types of information to be introduced early in the decision-making process. ${ }^{49}$ Similarly, the analysis of alternatives 'considering their risks and the technical and economic feasibility of substitution' 50 allows for the integration of non-scientific information into the application stage.

\section{Stage 2: Review}

The dominant player in the second or 'review' stage of the authorisation process is the European Chemicals Agency (ECHA). ECHA receives applications directly from manufacturers, importers and downstream users, and produces a draft opinion on whether the reviewed substance should be authorised for (continued) sale and/or use, and on the applicable conditions for authorisation. ECHA, which opened shop in mid-2007, and which will gradually expand its regulatory, administrative and advisory operations to meet all the responsibilities assigned to it in the REACH Regulation by 2010, is an independent European Community Agency, conceived and structured along similar lines as the European Food Safety

46 This stage comprises identification of intrinsic properties and establishment of dose-response relationships in order to determine either Derived No-Effect Levels (DNELs) or Predicted No-Effect Concentrations (PNECs).

47 Derived No-Effect Levels.

48 Predicted No-Effect Concentrations.

${ }^{49}$ But see below (Inclusiveness through Integration).

${ }^{50}$ REACH Reg., n 15 Above, Art. 62(4)(e). 
Agency (EFSA). ${ }^{51}$ Thus, at first glance the review stage of the authorisation process should be heavily technocratic, dominated by a group of independent, unelected civil servants located in the beautiful but rather remote Helsinki. However, to represent the review stage as purely technocratic, and in the hands of one monolithic institution, rather underplays the complexity of the review process for two reasons.

First, it does not take into account the checks and balances built into the authorisation process. Once an application is submitted to ECHA, it forwards the application dossier to its Committee for Risk Assessment (CRA) and its Committee for Socio-Economic Analysis (CSEA) to produce a draft opinion within 10 months of submission. Consultation with 'third interested parties' is foreseen in Article 64(2) of the REACH Regulation. Beyond this provision, CSEA can ask either the applicant or third parties to give additional information on substitutes, and both Committees are to 'take into account any information submitted by third parties. ${ }^{52}$ Once the draft opinion is ready, the applicant is invited to comment upon it. ${ }^{53}$ If the applicant avails herself of this opportunity, the ECHA Committees must consider the comments before producing their final opinion. ECHA then forwards the final opinion, together with the applicant's comments, to the Commission, the Member States, and the applicant. If the applicant does not comment, the draft opinion is confirmed as a final opinion and passed on to the Commission, the Member States, and the applicant.

Second, it pays to take a closer look at the institutional set-up of ECHA, and the inclusiveness of representation within the organisation. ${ }^{54}$ In a nutshell, the Agency is run by an Executive Director (Geert Dancet) and Management Board of 32. Each Member State appoints a member to the Board. Of the remaining five, two are appointed by the EP, and three by the European Commission. The latter include one industry, one employees and one NGO representative (without voting rights). ${ }^{55}$ ECHA's work load will be spread over six planned Directorates, most of which will be staffed by scientifically trained personnel. However, Directorate A is destined to house a unit for international cooperation and stakeholder relations, which will inter alia be responsible for risk communication with and between the various stakeholders. Moreover, ECHA will be assisted by three Committees and a Forum ${ }^{56}$. The Member State Committee is the main channel through which national interests are to be represented internally. Additionally there are the aforementioned CRA and CSEA. The latter particularly would seem to constitute

\footnotetext{
51 Regulation (EC) No 178/2002 of the European Parliament and of the Council of 28 January 2002 laying down the general principles and requirements of food law, establishing the European Food Safety Authority and laying down procedures in matters of food safety [2002] OJ L31/1.

52 REACH Reg., n 15 above, Art. 64(3).

53 ibid, Art. 64(5)

54 See http://ec.europa.eu/enterprise/reach/docs/calls/ed_echa_organisation.pdf.

55 'Chemicals Agency Finalises Director, Budget', ENDS Europe Daily 2451, 17 December 2007. See also http:/ /echa.europa.eu/about_en.html.

56 'The Forum will support Member States' coordination of enforcement activities. Furthermore, the Commission is assisted by a 'High Level Chemical Group,' see 'EU High Level Chemical Group Gives First Report', ENDS Europe Daily 2454, 20 December 2007.
} 
a locus for non-scientific risk considerations to be integrated into the authorisation review process.

\section{Stage 3: Decision}

Finally, the Commission heads the decision stage of the authorisation process. It formulates a proposal on the basis of the final opinion delivered by ECHA, which is adopted following the regulatory comitology procedure. ${ }^{57}$ The regulatory procedure requires committee approval by qualified majority for the adoption of the proposal to go forward. In the absence of a positive qualified majority within the committee, the Commission must forward a measure relating to the proposal to the Council, which has the option to reject it by QMV within three months. In the absence of a Council rejection, or if the Council comes out in favour of the Commission's proposal, the Commission adopts the measure. In the context of the REACH authorisation procedure, three points are of particular interest. First, even though it is the procedure of choice for several other implementing mechanisms under $\mathrm{REACH},{ }^{58}$ the newly introduced regulatory procedure with scrutiny (RPWS) ${ }^{59}$ is not appropriate for the adoption of authorisations, since the latter are executive measures rather than quasi-legislative measures. ${ }^{60}$ The EP's involvement will therefore be restricted to the alarm bell procedure set out in Articles 5(5) and 8 of the 1999 Comitology Decision. Second, the reference to the regulatory procedure is an amendment to the original text of the $\mathrm{REACH}$ Regulation, according to which authorisation decisions followed the advisory procedure. ${ }^{61}$ In the realm of comitology, the advisory procedure is unequivocally the most supranational of the implementing decision-making processes. The Commission is bound to obtain and take account of the advice of a committee of Member State representatives, however, the Commission has the authority of adopt its proposal even in the face of a negative committee opinion. Although the shift from advisory to regulatory procedure was played off in the press as a minor adjustment, ${ }^{62}$ it represents an important recalibration between the national and supranational influences in what will certainly be the most controversial and politically sensitive decision-making procedure under the REACH umbrella. Finally, with regard to the substantive decision on authorisation, the Commission's discretion differs depending on whether the applicant can show that the risks are 'adequately controlled'. If so (in other words, if the applicant can make a plausible case that the known or anticipated exposure will not exceed the no-effect exposure), Article 60(2) in principle requires the Commission to authorise marketing and/or use. The Commission only has discretion to refuse an authorisation where risks are not adequately controlled. In this case, the

${ }^{57}$ Council Decision 1999/468/EC [1999] OJ L184/23, Art. 5.

${ }^{58}$ Such as the adoption of marketing and use restrictions, see Part III above.

${ }^{59}$ Dec. 1999/468/EC, as amended, n 57 above, Art. 5(a).

60 See G. Schusterschitz \& S. Kotz, 'The Comitology Reform of 2006. Increasing the Powers of the

European Parliament without Changing the Treaties' (2007) 3 European Constitutional Law Review 68, 80.

${ }^{61}$ Dec. 1999/468, n 57 above, Art. 3.

${ }^{62}$ 'Verheugen Charts Green Path for EU Business’ ENDS Europe Daily 2289, 23 Mar. 2007. 
authorisation and conditions will hinge on the risk-benefit ratio which commercialisation of the substance represents, and the availability of alternatives. ${ }^{63}$ It should be noted in this context that, for many $\mathrm{PBT}, \mathrm{vPvB}$ and $\mathrm{CMR}$ substances, it is at the moment scientifically impossible to define a safe level. ${ }^{64}$ These fall under the category of "not adequately controlled", and will therefore be subject to a substitution requirement and discretionary decision-making.

\section{OUTPUT}

What are the provisions and conditions to engage with the outcome of an EU regulatory process, in this case, the Commission decision to approve grant or withhold authorisation? Beyond the purely informal (though powerful) avenue of openly praising or criticising a Commission decision in the media, stakeholders need to resort to judicial review mechanisms. The notoriously unforgiving nature of access to justice conditions for non-privileged applicants (ie, stakeholders other than the main Community institutions, the Member States, and the party/parties to whom the decision is addressed) under Article $230 \mathrm{EC}$ has been exhaustively documented and reviewed, ${ }^{65}$ and need not be repeated here. It is, however, useful to point out that, in 2006, a ray of light appeared in the form of Regulation (EC) No. 1367/2006 on the application of the provisions of the Aarhus Convention on Access to Information, Public Participation in Decision-making and Access to Justice in Environmental Matters to Community Institutions and Bodies (the Community Institutions and Bodies Regulation). ${ }^{66}$ As to access to information, Articles 11 to 13 of the Regulation require the availability of databases or registers giving information on, inter alia, authorisations with a significant impact on the environment, thus further strengthening the publicity requirements under the REACH Regulation. ${ }^{67}$ Moreover, Title IV of the Regulation provides that environmental NGOs, provided they have the qualifications spelled out in Article 10 , can make a request for internal review to a Community institution or body that has adopted an administrative act under environmental law. This provision could be relied upon by environmental NGOs to request review of Commission decisions pertaining to chemicals authorisations. If authorisations are indeed understood as 'administrative acts under environmental law' - and there could be some debate about this - then the availability of internal review is indeed a further

63 REACH Reg., n 15 above, Art. 60(4).

64 B. Hansen \& M. Blainey, 'REACH: A Step Change in the Management of Chemicals' (2006) 15 RECIEL 270, 277.

65 See, among others, J. Usher, 'Direct and Individual Concern - An Effective Remedy or a Conventional Solution?' (2003) 28 ELR 575; AG Jacobs' Opinion in Case C-50/00 Unión de Pequeños Agricultores v Council [2002] ECR I-6677; C. Koch, "Locus Standi” of Private Applicants under the EU Constitution: Preserving Gaps in the Protections of an Individual's Right to an Effective Remedy (2005) 40 ELR 511; and M-P Granger, 'Towards a Liberalisation of Standing Conditions for Individuals Seeking Judicial Review of Community Acts: Jégo-Quéré et Cie SA v Commission and Unión de Pequeños Agricultores v Council' (2003) 66 MLR 124.

66 [2006] OJ L264/13.

67 REACH Reg., n 15 above, Arts. 118-119. 
step towards inclusiveness. However, we do need to be aware of the Regulation's limitations. First, it only grants review opportunities to NGOs, and environmental NGOs at that. Other public interest groups, and private actors operating outside of the framework of an NGO, remain excluded. Second, the provision is for internal, not judicial review. A 2006 ECJ ruling confirmed that the provisions of the Community Institutions and Bodies Regulation have to be read in compatibility with Article 230 EC, and cannot be deployed so as to bypass the stringency of its provisions. ${ }^{68}$

\section{A CONTEXTUAL APPRAISAL OF INCLUSIVENESS}

Reviewing the inclusiveness of the REACH framework at the stages of input, throughput, and output, there is certainly some cause for satisfaction. Broad-based consultation and debate enriched to the point of nearly overburdening the legislative reform process. Interested third parties have an opportunity to submit information during the authorisation process. Engagement at the output stage is still the weak link of the governance regime, ${ }^{69}$ but the new Community Institutions and Bodies Regulation may at least create some form of access for a limited category of stakeholders relating to some of the public concerns regarding the control of chemicals.

The apparent high level of inclusiveness described in the preceding section should not come as a shock. REACH is, after all, the culmination of an intensive and high-profile nine year review process; its provisions have been carefully plotted and exhaustively discussed and negotiated in a wide-spanning array of public and private settings, in regional, national, European, and international fora. The European Community is, by now, an experienced risk regulator, enlightened by past controversy and regulatory failure in areas such as pharmaceuticals control, chemicals, and GMO regulation, and therefore unlikely to design new regulatory frameworks that overtly and bluntly sideline major stakeholders and interests. Yet, whether the provisions in REACH will secure full and effective public participation remains dishearteningly doubtful, particularly when we take into consideration the context in which participation takes place.

\footnotetext{
${ }^{68}$ Case T-94/04 European Environmental Bureau (EEB), Pesticides Action Network Europe, International Union of Food, Agricultural, Hotel, Restaurant, Catering, Tobacco and Allied Worker's Associations (IUF), European Federation of Trade Unions in the Food, Agricultural and Tourism sectors and allied branches (EFFAT), Stichting Natuur en Milieu and Sevenske Naturskyddföreningen v. Commission [2005] ECR II-4919. See also joined cases T-236/04 and T-241/04 European Environmental Bureau (EEB) and Stichting Natuur en Milieu v. Commission [2005] ECR II-4945.

${ }^{69}$ Cf O. De Schutter, 'Europe in Search of its Civil Society' (2002) 8 ELJ 214.
} 


\section{The Terms OF ARTICLE 64(2) REACH}

A first and smaller point relates to the exact terms of the provisions on public consultation in the framework of an authorisation application. Article 64(2) of REACH stipulates that: 'The Agency shall make available on its web-site broad information on uses (..)for which applications have been received and for reviews of authorisations, with a deadline by which information on alternative substances or technologies may be submitted by interested parties.' Now, it is reasonable to expect ECHA to interpret this provision broadly, if necessary after some prodding by the ECJ, but it nevertheless remains pertinent that Article 64(2) allows ECHA to construct and, hence, select the body of information to be disclosed. More worrying is the explicit reference to information on alternative substances and technologies. For reasons of commercial confidentiality alone, this is not the type of information that will typically be at the disposal of non-industrial stakeholders. It would probably go too far to argue that Article 64(2) should be read to exclude the submission of information submitted by interested third parties and relating to other issues than substitution, particularly when read in conjunction with of the new Community Institutions and Bodies Regulation, however it may at least foster an informal prioritisation of information on alternative substances and technologies and, hence, of those (industrial) stakeholders that possess this type of knowledge.

\section{STRUCTURED VERSUS UNSTRUCTURED ACCESS}

A more general observation relates to how the dialogue between public authority and third parties is structured. An invitation is more welcoming than an unlocked door. Or, in the context of REACH, explicit solicitation of opinions, as for instance provided through the forwarding of draft opinions to applicants, accompanied by a request for comments, ${ }^{70}$ fosters a more productive exchange than a simple permission to comment. This, in turn, can significantly improve the effectiveness of participation. ${ }^{71}$ Reviewing the participatory arrangements under REACH, we observe that exchanges with applicants and with third parties who have information on substitution are more structured, and therefore arguably more conducive to genuine deliberation than those with other interested parties.

\section{THE SCOPE OF THE REACH REgULATION}

The degree of inclusiveness of EU regulation tends to be reviewed within the confines of a specific regulatory framework. However, stakeholder involvement in regulation is only meaningful if the regulation adequately covers those activities, practices, and arrangements over which stakeholders seek to express their interests

${ }^{70}$ REACH Reg., n 15 above, Art. 64(5).

${ }^{71}$ Obradovic \& Alonso Vizcaino, n 34 above, 1060-1061. 
and public concerns. In this scenario, if public concern relates to chemicals, or to aspects of their production, processing, or marketing that are not covered under $\mathrm{REACH}$, then these concerns cannot find adequate expression within the discursive space created by regulatory procedures. Reviewing the REACH Regulation, it is quickly apparent that this regime is much more inclusive in scope than its predecessor. As mentioned, it covers both old and new substances, and importantly includes substances in articles, which widens the reach of the Regulation to cover most industrial sectors. Whereas formerly information supply duties for new substances were only triggered upon marketing, registration is required for production, marketing and use. With the more inclusive substantive scope of application also comes a wider group of affected regulatory addressees, as REACH imposes obligations down the supply chain. However, REACH does have a regulatory blind spot, in that only chemicals produced or imported in volumes of at least 1 tonne per manufacturer and per year are subject to registration. This means that about 60,000 substances listed in the EINECS, many of which produced or traded in small but non-negligible quantities, are not processed and, hence, not debatable, within the regulatory system. Also, REACH excludes, inter alia, chemicals used in agriculture, biocides and cosmetics, which will continue to be governed by separate regulations. ${ }^{72}$ The inclusiveness of the EU regime for chemicals control can therefore only partly be guaranteed by REACH.

\section{INCLUSIVENESS THROUGH INTEGRATION}

A further contextual element to take into account is that we only obtain a narrow account of inclusiveness if we restrict our analysis to the development of formal, or even the formal and informal, channels of communication between public authorities and stakeholders under the auspices of regulation. Inclusiveness can however additionally be encouraged through the introduction of requirements that compel regulatory addressees to identify and take into account a broadened range interests within assessment and evaluation processes. Such integrative requirements can be particularly effective where exclusion is a consequence of oversight rather than deliberate action, and where regulatory addressees may derive potential benefits from interest integration.

REACH could be said to respond to this version of inclusiveness as it provides a more integrative approach to the successive steps of risk identification, risk assessment, and risk management than before. It requires private actors to draw up guidance notes for safe use and, for substances above a 10 tonne threshold, chemicals safety assessments (ie, risk assessments) and safety data

\footnotetext{
72 See N. de Sadeleer, 'The Impact of the Registration, Evaluation and Authorization of Chemicals $(\mathrm{REACH})$ Regulation on the Regulatory Powers of the Nordic Countries' in N. de Sadeleer (ed), Implementing the Precautionary Principle. Approaches from the Nordic Countries, EU and USA (London: Earthscan, 2007), 334, questioning whether the overlaps and possible contradictions between the different regimes have been adequately addressed within REACH.
} 
sheets as a precondition to registration. Thus, contextual factors pertaining to the use and anticipated or known exposure of a substance become attached to and can influence the initial risk identification process. The need to contemplate use and exposure, and to formulate protocols for safe use, may affect decisions on whether to pursue commercialisation of a new substance at an earlier stage in the engineering and design process, before massive costs are sunk in, and may impact on decisions on whether to apply for registration of older chemicals. This will hopefully foster a higher level of responsiveness to health and environmental concerns, and a stronger practice of self-selection within the chemicals industry, determined by more than the commercial viability of the contemplated product. Similarly, within the framework of the authorisation process, Article 55 of REACH insists that all manufacturers, importers and downstream users must analyse the availability of alternatives and consider their risks and the technical and economic feasibility of substitution. This opens up opportunities for a selfimposed, early, perhaps rather rudimentary comparative risk assessment that can weed out the more obvious cases where substitutions should be made, thus obviating the need for a lengthy, vexatious and perhaps ultimately unsuccessful authorisation procedure..$^{73}$

We should take care however not to overstate the extent or the promises of integrated assessment requirements. The overwhelming majority of substances subject to REACH are marketed in volumes of between one and ten tonnes per year. Registration of this category of substances does not require a chemicals safety report (risk assessment). Thus, for an estimated 30,000 substances, the new chemicals control policy will mainly consist of an information gathering and limited testing exercise. Apart from the requirement to supply available guidance notes for safe use, very little scope exists for risk considerations, whether of a scientific, social or economic nature, to be integrated into the control process. Koch and Ashford have voiced a concern that, for most chemicals, the REACH framework will amount to little else than data collection and box-ticking. ${ }^{74}$

Moreover, even within the narrowly delineated field of testing data to be produced in compliance with the registration provisions, questions emerge as to the effectiveness of the Regulation's inclusive approach to health and environmental protection. The process of hazard identification and short term toxicity testing may generate plausible results for human health assessments, but it is notoriously feeble when it comes to the identification of environmental risks. In light of, to name but a few factors, the endless variety of recipients within ecosystems, the scope for synergic impacts caused by multiple exposure and opportunities for long term build-up and mutation, the snap-shot, substance-bysubstance approach in laboratory testing makes for a poor predictor of

${ }^{73}$ L. Koch \& N. Ashford, 'Rethinking the Role of Information in Chemicals Policy: Implications for TSCA and REACH' (2006) 14 Journal of Cleaner Production (2006) 31, 40.

74 ibid, 45. 
environmental impacts. ${ }^{75}$ More robust assessments generally require a combination of testing, epidemiological studies and monitoring mechanisms. ${ }^{76} \mathrm{On}$ the latter aspects, REACH is particularly weak. It is interesting to observe that the critiques on the effectiveness of the data gathering provisions for environmental risk control are not new; they have been around since well before the 1998 review. ${ }^{77}$ However, in contrast to the criticism on the expediency of the former regulatory framework to deliver regulatory outcomes, they were not included or addressed in the reform process.

Finally, where the REACH framework does provide an opportunity for the inclusion of contextual, socio-economic information within the earlier stages of identification and assessment, we need to ask ourselves exactly what can be included. We recall that, within the authorisation procedure, the applicant may include a socio-economic analysis (SEA), details for which are mapped out in Annex XVI to the Regulation. When reviewing the elements that an SEA may cover, it is hard to escape the conclusion that this is overwhelmingly conceived as an opportunity for the applicant to mitigate any unfavourable indications in the risk assessment; there is a strong emphasis on the predicted impact of a refusal on industry, on pricing and consumer choice, on job security and employment, and on trade and competitiveness. A reference to consumer and environmental health effects cuts a lonely figure compared to the plethora of economic impacts to be considered. Moreover, no mention is made of any information relating to risk perception or risk communication. In any event, since the SEA will be drawn up by applicants for authorisation, their incentives to include information that might strengthen the case for risk control are highly dubious.

\section{THE ORgANISATION OF INTEREST REPRESENTATION}

Beyond the challenges posed by the disparities in access for different groups of stakeholders, and by the substantial limitations of the terms of the regulatory debate, lies the even more intractable problem of uneven resources and expertise. Collective action and free rider problems make it a sure bet that public interest representation will be under-resourced compared to private interest groups. This is certainly the case for the area of chemical control, where one of the major stakeholders, the chemicals industry, constitutes Europe's third largest industry, employing approximately 1.7 million people, with another 3 million employees in

\footnotetext{
${ }^{75}$ See n 2 above, 126-130.

${ }^{76}$ S. Dobson, Why Different Regulatory Decisions When the Scientific Information Base is Similar Environmental Risk Assessment (1993) 17 Regulatory Toxicology and Pharmacology 333.

77 Eg, K. Ladeur, 'Risikowissen und Risikoentscheidung. Kommentar zu Gotthard Bechmann' (1991) 74 Kritische Vierteljahresschrift fuer Gesetzgebung und Rechtswissenschaft (1991) 241, 249; V. Norberg-Bohm, W. Clark, B. Bakshi, J. Berkenkamp, S. Bishko, M. Koehler, J. Marrs, C. Nielsen \& A. Sagar, 'International Comparisons of Environmental Hazards: Development and Evaluation of a Method for Linking Data with the Strategic Debate on Management Priorities for Risk Management" (1992) Working Paper of the Center for Science \& International Affairs, John F. Kennedy School of Government, 7.
} 
jobs that are directly dependent on the chemicals sector. ${ }^{78}$ It is also a rather apprehensive industry, as in the last seven years growth rates in the chemical sector, both within EU-25 and globally, have consistently lagged behind overall industrial growth rates. ${ }^{79}$ As indicated before, public interest NGOs did participate vigorously, and some commentators assert quite successfully, ${ }^{80}$ in the REACH negotiation process, but it is undeniable that the chemical industry's resources and specialised expertise far outstrip their own, which hampers their ability to participate in decision-making as effectively as commercial interest representatives. This disequilibrium is pushed further by the fact that public interest NGOs tend to have wide portfolios, and therefore need to be very strategic and selective in their allocation of resources. Thus, the elevated level of NGO participation in the 'input' phase of REACH does not necessarily imply there will be a similarly heavy involvement in 'throughput' and 'output'. A 2007 article in the ENDS Report on new institutional developments within WWF does convey the impression that chemical control is considered a finished project: '(the) finalisation of the EU's REACH chemicals regime marks the end of an era. WWF now wants to focus on climate and resources with its "one living planet" agenda.(...) Chemicals is one of the areas which has fewest cross-overs with climate and benefits least from its high profile. WWF is certainly not alone in dropping its chemicals campaigning - a relatively technical topic that can be difficult to explain to the public.' ${ }^{91}$ If this is indeed a marker of a more general trend, we might wonder whether NGOs have not missed a trick, since the real impact of substantive risk control requirements hinges to a considerable extent on their interpretation and application, and it is therefore crucial to be involved in the interpretation and application process.

\section{CONCLUSION}

The sober tones of the last few paragraphs above notwithstanding, it would be unfair, and unproductive, to condemn the REACH framework for lack of inclusiveness. Compared to the old regulatory framework for chemicals control, great improvements have been made in terms of the openness of the debate leading to the adoption of REACH. Moreover, REACH does provide a good level of transparency 82 -- a prerequisite for any form of workable participation -- and some opportunity for consultation. Access to justice remains a weak link, but the 2006 Community Institutions and Bodies Regulation might create a modest and

\footnotetext{
78 CEFIC, Barometer of Competitiveness 2002, Business impact of New Chemicals Policy, published on the Internet at: http://www.cefic.org/Files/Publications/Barometer2002.pdf.

79 CEFIC Facts and Figures, December 2006, published in the Internet at: http://www.cefic.be/ factsandfigures/downloads/CHapter\%203.pdf.

${ }^{80}$ But see $n 41$ above, 111 .

81 'Chemicals NGO Forms as Climate Takes Centre Stage' ENDS Report, May 2007, Issue 388, 5.

82 REACH Reg., n 15 above, Arts. 118-119.
} 
partial scope for ex-post scrutiny. On balance, this is a reasonably good scorecard from the point of view of inclusive governance.

However, a contextual appraisal does indicate that the participatory and integrative arrangements incorporated in REACH are very brittle, and casts serous doubts over whether REACH will result in genuinely inclusive risk management. The organisation of consultation, the scope of the Regulation, the selection of criteria and reference points to be integrated in assessment and management processes, and the perennial problem of relative lack of support and funding for NGO involvement, all conspire to erode, even trivialise, the inclusive nature of the decision-making framework. This echoes a message long familiar to those active in anti-discrimination law: the provision of formal equality is the beginning, not the end of a reform process towards an inclusive, non-discriminatory society. Drawing the parallel, and recalling that REACH still falls short of full formal 'equality' for all stakeholders in terms their opportunities for engagement with regulation, the new EU regime for the control of chemicals could be said to constitute a first firm step towards the beginning of a reform process leading to inclusive governance in risk regulation. 